\title{
How do Students Learn to See Concepts in Visualizations? Social Learning Mechanisms with Physical and Virtual Representations
}

\author{
Martina A. Rau \\ Department of Educational Psychology \\ University of Wisconsin-Madison, USA \\ marau@wisc.edu
}

\begin{abstract}
STEM instruction often uses visual representations. To benefit from these, students need to understand how representations show domain-relevant concepts. Yet, this is difficult for students. Prior research shows that physical representations (objects that students manipulate by hand) and virtual representations (objects on a computer screen that students manipulate via mouse and keyboard) have complementary advantages for conceptual learning. However, physical and virtual representations are often embedded into different social classroom contexts, which may affect social mechanisms through which students construct connections between concepts and representations. Therefore, this paper focuses on the social events that precede concept-representation connections. Twelve high-school students worked collaboratively with physical and virtual representations of chemistry. Frequent pattern mining of discourse data was used to identify social events that often preceded concept-representation connections. Qualitative analysis investigated social mechanisms through which these events may enhance concept-representation connections. Results show that students construct conceptrepresentation connections incrementally. Further, meta-cognitive strategies and instructor prompts often preceded concept-representation connections. Finally, differences between physical and virtual representations were mainly due to different social supports being available in the context in which the representations were embedded. I discuss contributions to literature on learning with multiple representations and to interventions that blend representation modes.
\end{abstract}

Keywords: Physical and virtual representations, chemistry, collaborative learning, frequent pattern mining, discourse

\section{INTRODUCTION}

Novice students in science, technology, engineering, and math (STEM) domains grapple with a representation dilemma (Dreher \& Kuntze, 2014): they use visual representations they have never seen before to make sense of concepts they have not yet learned. Educators often assume that students can see meaningful concepts in the representations (Airey \& Linder, 2009; Uttal \& O'Doherty, 2008); however, much evidence shows that students struggle in connecting concepts to representations (Gilbert, 2005; McElhaney, Chang, Chiu, \& Linn, 2015). Their failure to make concept-representation connections can severely impede their learning (NRC, 2006). For example, chemistry students' difficulties in making concept-representation connections impedes their learning of key concepts (Justi \& Gilbert, 2002; Strickland, Kraft, \& Bhattacharyya, 2010). This issue applies to all STEM domains: 
(2017). How do students learn to see concepts in visualizations? Social learning mechanisms with physical and virtual representations. Journal of Learning Analytics, 4(2), 240-263. http://dx.doi.org/10.18608/jla.2017.42.16

because many concepts cannot be directly observed (Gilbert, 2005; Kozma \& Russell, 2005b), STEM instruction relies on visual representations (Ainsworth, 2008; Kozma \& Russell, 2005b; Wertsch \& Kazak, 2011). Thus, STEM instruction needs to help students construct connections between concepts and representations (Ainsworth, 2006).

Both sociocultural and cognitive theories of learning can help us understand how students learn to see concepts in visual representations (Rau, 2016). According to sociocultural theories, students construct connections between concepts and visual representations via socially mediated processes (Vygotsky, 1978; Wertsch, 1997; Wertsch \& Kazak, 2011), for example, when students use representations to solve problems, discuss ideas, and make sense of complex phenomena (Airey \& Linder, 2009; Wertsch \& Kazak, 2011). Through these social interactions, students learn how visual representations depict concepts. Thus, to support student learning, we need to understand through which social mechanisms they construct concept-representation connections.

According to cognitive theories, students construct concept-representation connections by relating visual features to meaningful referents (Ainsworth, 2006; Schnotz, 2005, 2014). To make such connections, students need to explain principles of how visual representations depict information (Chi, Bassok, Lewis, Reimann, \& Glaser, 1989; Gentner, 1983). Students often fail to spontaneously explain connections (Ainsworth, Bibby, \& Wood, 2002; Rau, Aleven, Rummel, \& Pardos, 2014). Therefore, instructional interventions need to help students construct such connections by prompting them to explain how visual representations show concepts, a process that helps students deepen their understanding of the concepts themselves (Bodemer \& Faust, 2006; Rau, Aleven, \& Rummel, 2015; Seufert \& Brünken, 2006). Thus, to support student learning, we need to understand what prompts students to construct concept-representation connections.

Visual representations can be presented physically (e.g., a tangible model that students can manipulate with their hands) or virtually (e.g., a digital model on a computer screen that students can manipulate via mouse or keyboard). Recent research suggests that these different representation modes have different affordances for student ability to learn how they depict yet-to-be-learned concepts (de Jong, Linn, \& Zacharia, 2013; Manches, O'Malley, \& Benford, 2010). Most of this research has focused on cognitive affordances. However, physical and virtual representations are typically embedded in social contexts that differ in terms of how students interact with one another and with their instructors. Hence, it is conceivable that these social contexts also have different affordances for student ability to construct concept-representation connections. Therefore, this paper investigates how social contexts in which physical and virtual representation modes are embedded shape the social mechanisms through which students construct concept-representation connections. At a theoretical level, this research will help us understand the social mechanisms by which representation modes affect student ability to navigate the representation dilemma. At a practical level, it will inform the design of interventions that combine or blend physical and virtual representation modes. 
(2017). How do students learn to see concepts in visualizations? Social learning mechanisms with physical and virtual representations. Journal of Learning Analytics, 4(2), 240-263. http://dx.doi.org/10.18608/jla.2017.42.16

\section{$1.1 \quad$ Prior Research}

Research in many STEM domains - including chemistry - shows that the representation mode affects student ability to learn new concepts (de Jong et al., 2013; Manches et al., 2010). Physical representations are tangible objects that students manipulate by hand. Figure 1 (a-d) shows physical representations often used in chemistry instruction. Physical representations can make concepts intuitively accessible because they provide haptic input (Bakker, Antle, \& Van Den Hoven, 2012) and because students can manipulate them via simple actions that result in continuous, gradual changes (Chini, Madsen, Gire, Rebello, \& Puntambekar, 2012; de Jong et al., 2013; Manches et al., 2010). By contrast, virtual representations are digital visualizations presented on a computer screen that students manipulate via mouse or keyboard (Figure 1, e-h). They can make concepts visible that cannot be observed with the regular eye (de Jong et al., 2013; Jaakkola, Nurmi, \& Veermans, 2011; Manches et al., 2010). They can also address misconceptions by providing immediate feedback on their manipulations (Clements, 1999).

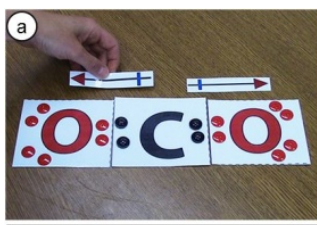

(อ)

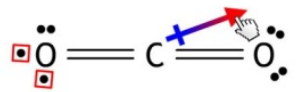

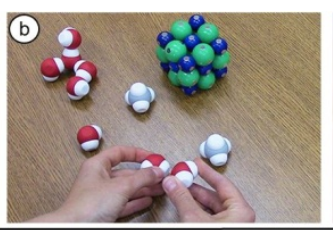

(†)

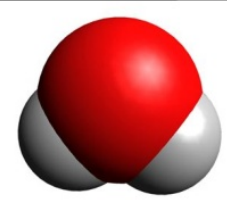

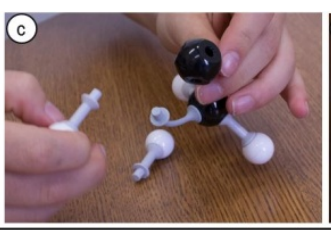

(g)

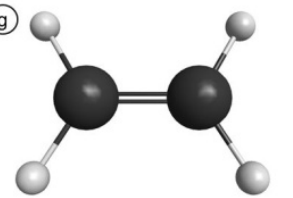

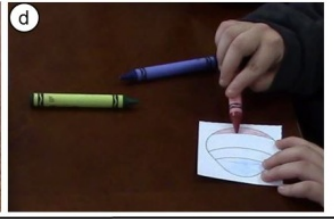

Physical representations:

a: Lewis structure of carbon dioxide

b: Space-filling model of water c: Ball-and-stick figure of ethene

d: EPM of hydrogen fluoride

(1)

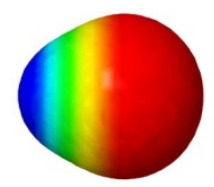

Virtual representations:

e: Lewis structure of carbon dioxide

f: Space-filling model of water g: Ball-and-stick figure of ethene

$h$ : EPM of hydrogen fluoride

Figure 1: Physical representations (a-d) and virtual representations (e-h) of chemical molecules.

This research suggests that physical and virtual representations have complementary cognitive affordances for student conceptual learning (de Jong et al., 2013; Klahr, Triona, \& Williams, 2007; Olympiou \& Zacharia, 2012). Physical representations have been shown to be particularly effective in helping students learn concepts that build on movement or real-world experiences such as taking measures (Zacharia, Loizou, \& Papaevripidou, 2012), feeling weights (Zacharia et al., 2012), or understanding how scientists collect data in concrete contexts (Winn et al., 2006). Virtual representations have been shown to be effective in helping students learn concepts that describe invisible processes such as electron flow (Finkelstein et al., 2005) or chemical bonding (Zhang \& Linn, 2011), summarizing data (Winn et al., 2006), or when removing concrete details can make concepts more salient (de Jong et al., 2013). Building on these findings, research has investigated how best to combine physical and virtual representations in instructional interventions. Such "blending interventions" (Olympiou \& Zacharia, 2012) combine representation modes based on a priori analyses of their cognitive affordances.

In addition, physical and virtual representations may have different social affordances for student learning. When used in classrooms, physical and virtual representations are typically embedded in 
(2017). How do students learn to see concepts in visualizations? Social learning mechanisms with physical and virtual representations. Journal of Learning Analytics, 4(2), 240-263. http://dx.doi.org/10.18608/jla.2017.42.16

different types of social contexts. Students usually work with physical representations as part of collaborative problem-solving exercises (Bodner \& Domin, 2000; Michalchik, Rosenquist, Kozma, Kreikemeier, \& Schank, 2008). This context often involves considerable instructor support, because students have to rely on their instructor for help in making sense of concepts and to solve problems (Boulter \& Gilbert, 2000). By contrast, virtual representations are typically embedded in educational technologies that allow students to manipulate virtual representations to solve domain-relevant problems (Dori \& Barak, 2001; Kozma \& Russell, 2005a). In this context, students may work individually or collaboratively (Tortosa, 2012; Wu, Krajcik, \& Soloway, 2001). This context often involves less instructor support because - although students may receive some help from their instructor educational technologies typically provide considerable help and feedback as students use representations to solve problems (Wu et al., 2001).

Understanding how such social contexts affect student ability to construct concept-representation connections is important because learning with representations is often mediated by social processes. For example, students engage in collaborative activities to co-construct meaning of representations (Roschelle, 1992). During this social process, particular social events may encourage conceptrepresentation connections (e.g., prompting by an instructor, disagreement with another student). These social events may differ by representation mode because they are typically embedded in different social contexts. However, prior research has not yet investigated how physical and virtual representations affect connection making by virtue of being embedded in different social contexts. Addressing this question may also inform the design of blending interventions because instructional designers not only have to design the blending interventions but also the social contexts in which they are implemented.

\section{$1.2 \quad$ Research Questions}

The goal of this paper is to understand social mechanisms through which students construct conceptrepresentation connections when they work with physical and virtual representation modes within their respective social context. A multiple-case study compared (1) student pairs working collaboratively with physical representations with immediate access to an instructor assigned to their group and (2) student pairs working collaboratively with virtual representations embedded in an educational technology while having immediate access to an instructor circulating the classroom. All students worked on problems that targeted the same chemistry concepts. To identify social events that frequently preceded conceptrepresentation connections, I applied frequent pattern mining to student-student and studentinstructor discourse. This analysis identified such social events for both representation modes and social events specific to a particular representation mode. A qualitative analysis investigated the mechanisms through which these social events might have helped students construct concept-representation connections. 
(2017). How do students learn to see concepts in visualizations? Social learning mechanisms with physical and virtual representations. Journal of Learning Analytics, 4(2), 240-263. http://dx.doi.org/10.18608/jla.2017.42.16

\section{METHODS}

\section{$2.1 \quad$ Multiple-Case Study}

Participants. The study took place at a high school in the Midwestern United States. The high school was a small environmental charter school with a total enrollment of 32 students in grades 7-12. The school emphasizes hands-on, self-directed collaborative learning. The study was conducted as part of a chemistry workshop organized by the research team. Out of the 32 students at the high school, twelve chose to participate in the workshop ( $n=1$ in grade 7, $n=3$ in grade $8, n=3$ in grade 9, $n=5$ in grade 12). These twelve students had very limited prior knowledge about chemical bonding and no prior experience with the visual representations.

Study Design. The study took place on three days spread across four weeks in spring 2015. Each study day was three hours long. Prior to the first day, the class teacher gave a brief introduction to chemical bonding. On the first day, students were introduced to the research team and received instruction on successful collaborative strategies. For the remainder of the study, students worked on the chemistry workshop materials. Days 1 and 2 were one week apart, days 2 and 3 were two weeks apart due to a school field trip. All students worked in randomly assigned pairs for the duration of the study. Each day covered a different type of chemical bond (non-polar covalent, polar covalent, and ionic bonds). For each study day, student pairs were randomly assigned to start with one representation mode (i.e., physical or virtual). To ensure that all students were exposed to all representation modes for each bond type, the students switched to the other representation mode half-way through the given class period.

Chemistry Workshop Materials. The workshop covered basic concepts related to chemical bonding. Students used visual representations to solve problems about polarity, octet rule, periodic table trends, and electronegativity. Students were presented with the visual representations shown in Figure 1: Lewis structures, space-filling models, ball-and-stick models, and electrostatic potential maps (EPMs). Each was presented in the physical and virtual mode.

When working with physical representations, students received a shared worksheet that asked them to construct a physical representation of a molecule, answer questions about concepts (e.g., about electronegativity) and about how the representation depicts the concepts. Students solved these questions with the physical representations (Figure $1 \mathrm{a}-\mathrm{d}$ ). Each student pair was assigned an instructor - a research assistant who was trained on facilitating student collaboration and on the chemistry concepts covered. Students were instructed to agree on an answer before writing it on their shared worksheet. If necessary, the instructor prompted students to agree on an answer before writing it down. Instructors provided feedback and assistance as students solved the problems on demand; they did not interfere unless students asked them to.

Virtual representations were integrated into an educational technology for chemistry - Chem Tutor (Rau, 2015), a type of intelligent tutoring system that focuses on connection making between visual 
(2017). How do students learn to see concepts in visualizations? Social learning mechanisms with physical and virtual representations. Journal of Learning Analytics, 4(2), 240-263. http://dx.doi.org/10.18608/jla.2017.42.16

representations and domain-relevant concepts. To this end, Chem Tutor presents virtual representations on the computer screen (see Figure $1 \mathrm{e}-\mathrm{h}$ ). The representations were interactive, so that students could manipulate them via mouse and keyboard input to solve problems about chemical bonding (see Figure 2). Chem Tutor prompts students to reflect on how each given visual representation depicts (or does not depict) particular concepts. Chem Tutor provides error-specific feedback and hints on demand, designed based on learner-centred studies. Chem Tutor leads to significant learning gains in chemistry knowledge and conceptual understanding of representations among college freshmen (Rau, 2015). While working with Chem Tutor, students could ask for help from an instructor who circulated the classroom. The instructor was readily available; no student group had to wait for the instructor to attend to them.

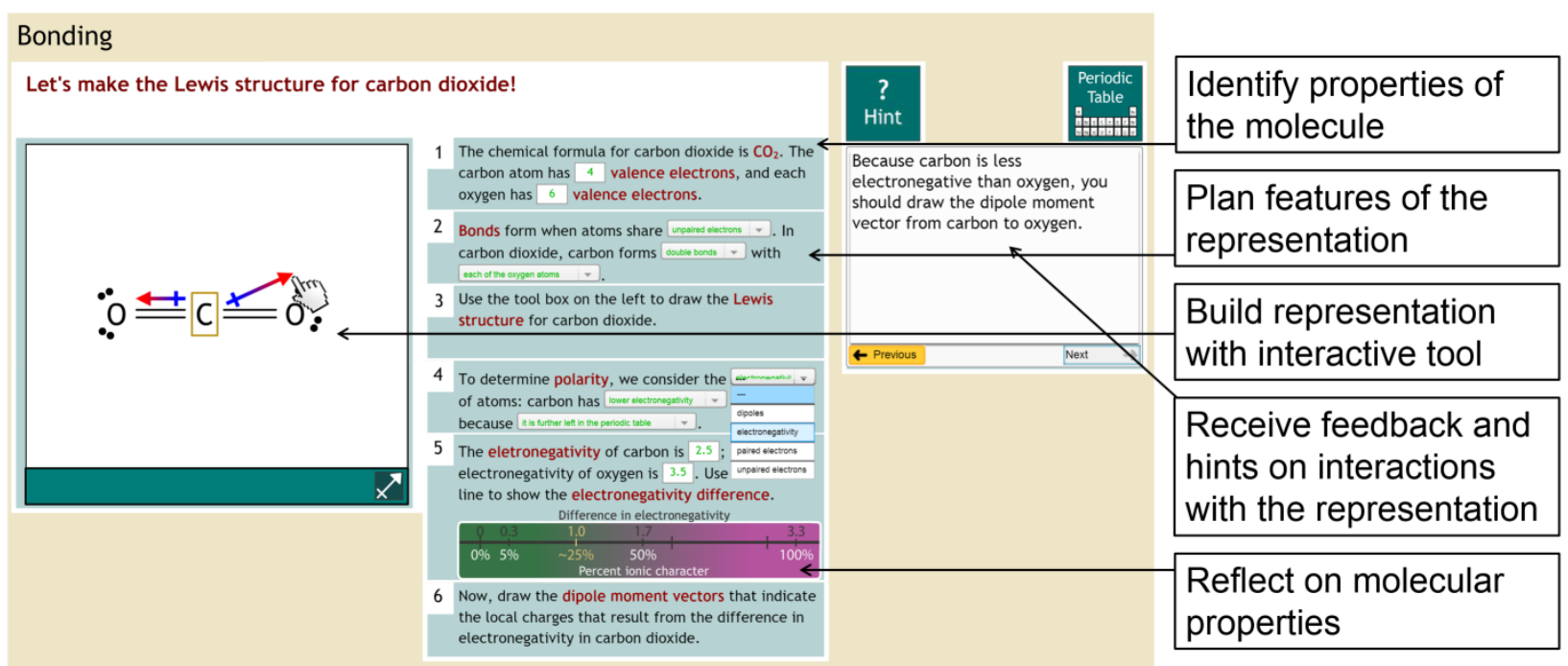

Figure 2: Example Chem Tutor problem that illustrates how students use an interactive tool to build a Lewis structure of carbon dioxide. Students receive hints and feedback on all problem-solving steps, including interactions with the representation.

\subsection{Analysis}

Grounded Theory Approach to Discourse Coding. All interactions among students and between students and instructors were video-taped and transcribed. Gestures were transcribed only if students pointed at a representation or at another resource in the classroom (e.g., periodic table, books, or posters). Transcripts were segmented by speaker turn. Altogether, the corpus contained 12,102 turns. To develop a coding scheme, I used a grounded theory approach (Muller, 2014; Saldana, 2016). Specifically, my research team summarized the entire corpus of transcripts utterance by utterance to discover emerging themes. Next, we formalized these themes as codes, and then applied the codes to utterances by students and instructors. The entire coding scheme comprises 45 codes with example utterances. Interrater reliability was established among three independent coders who had not been involved in developing the coding scheme. They applied the coding scheme to the same $6.8 \%$ of the corpus ( 820 
(2017). How do students learn to see concepts in visualizations? Social learning mechanisms with physical and virtual representations. Journal of Learning Analytics, 4(2), 240-263. http://dx.doi.org/10.18608/jla.2017.42.16

turns), composed of randomly selected worksheet/Chem Tutor questions and the corresponding utterances. Agreement was substantial with kappa $=.77$. Table 1 lists a subset of the codes.

Table 1: Subset of Codes in the Coding Scheme with Examples from the Transcripts

\begin{tabular}{|c|c|c|}
\hline Code & Definition & Example \\
\hline Concept & $\begin{array}{l}\text { Utterances that relate something to a } \\
\text { scientific concept }\end{array}$ & $\begin{array}{l}\text { "They want to be able to make a complete } \\
\text { number, a complete number of the eight on } \\
\text { the outside." }\end{array}$ \\
\hline $\begin{array}{l}\text { Concept- } \\
\text { request }\end{array}$ & $\begin{array}{l}\text { Suggesting/prompting utterances that } \\
\text { relate something to a concept }\end{array}$ & "What's the rule for the bonding?" \\
\hline $\begin{array}{l}\text { Representati } \\
\text { on }\end{array}$ & $\begin{array}{l}\text { Utterances that relate something to the } \\
\text { representation; utterances that explain } \\
\text { information shown by a representation }\end{array}$ & $\begin{array}{l}\text { [pointing at a representation] "So, one, two, } \\
\text { three, four, five. He have five"; [pointing at } \\
\text { a representation] "So, wait, that's carbon?" }\end{array}$ \\
\hline $\begin{array}{l}\text { Representati } \\
\text { on-request }\end{array}$ & $\begin{array}{l}\text { Suggesting/prompting utterances that } \\
\text { relate something to the representation; } \\
\text { utterances that explain information } \\
\text { shown by a representation }\end{array}$ & $\begin{array}{l}\text { "By looking at the Lewis structure, can you } \\
\text { answer the question about } \\
\text { electronegativity?"; "What are these } \\
\text { things?" [points at dots in Lewis structure] }\end{array}$ \\
\hline Assent & Expression of approval or agreement & "Yeah"; “Okay”; "I know”; “Mmhmm." \\
\hline $\begin{array}{l}\text { Meta- } \\
\text { confusion }\end{array}$ & $\begin{array}{l}\text { Utterances about oneself that describe } \\
\text { confusion about how to proceed or about } \\
\text { a concept, or about not knowing a } \\
\text { concept }\end{array}$ & $\begin{array}{l}\text { "I don't know"; "This is very confusing"; } \\
\text { "Maybe"; "This is hard"; "So, now we're } \\
\text { stuck"; “I don't get it why it's lines." }\end{array}$ \\
\hline $\begin{array}{l}\text { Meta- } \\
\text { understandi } \\
\text { ng }\end{array}$ & $\begin{array}{l}\text { Utterances about oneself that describe a } \\
\text { novel insight or understanding of how to } \\
\text { proceed or of a concept }\end{array}$ & $\begin{array}{l}\text { "Got it"; "Well, I know that part"; "I like this } \\
\text { explanation"; "Then I was like, well, duh"; } \\
\text { "We've been making this so much harder } \\
\text { than it is!" }\end{array}$ \\
\hline Reading & $\begin{array}{l}\text { Reading the problem statement or } \\
\text { instructions or hints/feedback from Chem } \\
\text { Tutor }\end{array}$ & $\begin{array}{l}\text { "Well it says right here that, 'Choose the } \\
\text { letters that show each atom.'” }\end{array}$ \\
\hline Explanation & $\begin{array}{l}\text { Utterances that explain/elaborate a } \\
\text { concept }\end{array}$ & $\begin{array}{l}\text { "But when they say dinitrogen, means they } \\
\text { bonded"; "I'll give a little bit more help"; } \\
\text { "So, carbon has more electrons than } \\
\text { hydrogen." }\end{array}$ \\
\hline $\begin{array}{l}\text { Explanation- } \\
\text { request }\end{array}$ & $\begin{array}{l}\text { Suggesting/prompting utterances that } \\
\text { explain/elaborate a concept }\end{array}$ & $\begin{array}{l}\text { "So what do you think that that is?"; "Could } \\
\text { you try, try to put as a complete sentence"; } \\
\text { "But why?"; "How did you know?" }\end{array}$ \\
\hline Metaphor & $\begin{array}{l}\text { Utterances that use a metaphor, intuitive } \\
\text { example, embellished language to } \\
\text { describe an abstract concept }\end{array}$ & $\begin{array}{l}\text { "To make it lock on kind of"; "Can I borrow } \\
\text { your electrons?"; "It's the same pulling } \\
\text { forces"; "So, like magnetic, plus and minus." }\end{array}$ \\
\hline
\end{tabular}


(2017). How do students learn to see concepts in visualizations? Social learning mechanisms with physical and virtual representations. Journal of Learning Analytics, 4(2), 240-263. http://dx.doi.org/10.18608/jla.2017.42.16

Table 2: Transcript Showing Four Turns Before a Concept-Representation Connection (Turn \#5)

\begin{tabular}{|c|c|c|c|}
\hline$\#$ & Speaker & Utterance & Codes \\
\hline 1 & Brigid* & $\begin{array}{l}\text { Electronegativity are the same so makes it } \\
\text { covalent which is no difference. }\end{array}$ & Concept \\
\hline 2 & Adriana & $\begin{array}{l}\text { [reads] Does the Lewis structure show the } \\
\text { polarity? Why or why not? Um. I'd say... I feel } \\
\text { like no, be... Well, yeah. I don't know. }\end{array}$ & Reading; meta-confusion \\
\hline 3 & Brigid & What does polarity mean? & $\begin{array}{l}\text { Explanation-request; concept- } \\
\text { request }\end{array}$ \\
\hline 4 & Instructor & $\begin{array}{l}\text { Polarity means plus and minus. Polarity } \\
\text { means... This [points at representation] By } \\
\text { looking at this one, can you see it has like } \\
\text { electronegativity or stuff. Polarity means } \\
\text { that... }\end{array}$ & $\begin{array}{l}\text { Explanation; metaphor; } \\
\text { representation-request; concept- } \\
\text { request }\end{array}$ \\
\hline 5 & Adriana & $\begin{array}{l}\text { I mean, like yeah, it doesn't like show really } \\
\text { like the pulling or the not pulling or the same. }\end{array}$ & $\begin{array}{l}\text { Explanation; representation; } \\
\text { concept; metaphor }\end{array}$ \\
\hline
\end{tabular}

* All student names are fake.

Frequent Pattern Mining. The goal of the analysis was to identify social events that often preceded students' concept-representation connections and to investigate if these social events differ between physical versus virtual representations. To this end, I took the following steps:

1. Operationalize concept-representation connections

2. Operationalize social events of interest

3. Search for social events that frequently precede concept-representation connections

The first step was to operationalize the variable of interest: concept-representation connections. To this end, I identified discourse segments in which students connected a concept to a representation. The educational psychology literature defines concept-representation connections as establishing the relation between a visual feature in a representation and the domain-relevant concept it depicts (Ainsworth, 2006). Hence, I operationalized concept-representation connections as student utterances that correctly refer to both a concept and a representation. That is, I considered utterances that received both a concept code and a representation code (see Table 1 for definition of codes, and Table 2, turn \#5 for an example of an utterance with both codes).

The second step was to operationalize social events of interest. In principle, any social event is of interest. The present analysis focuses on verbal social interactions. Hence, I consider any aspect of student-student or instructor-student discourse: a concept, a word of encouragement, an evaluation, a meta-cognitive statement, a mistake, etc. Because I was interested in the social mechanisms of coconstruction (Roschelle, 1992), I defined two consecutive discourse turns prior to the conceptrepresentation connection as the unit of analysis (i.e., utterances by two different speakers). I 
(2017). How do students learn to see concepts in visualizations? Social learning mechanisms with physical and virtual representations. Journal of Learning Analytics, 4(2), 240-263. http://dx.doi.org/10.18608/jla.2017.42.16

segmented the discourse data in the following way. First, I identified turns with concept-representation connections. For example, in the example shown in Table 2, row 5, Adriana makes a conceptrepresentation connection. Second, I identified the two turns before the concept-representation connection and considered them as one case. Each case corresponds to the codes applied to two consecutive turns (i.e., the codes in rows 3 and 4 in Table 2). This case is labelled as conceptrepresentation connection present (i.e., a concept-representation connection occurs in the following turn). Third, I segmented the remaining discourse data such that the codes applied to two consecutive turns serve as one case (e.g., rows 1 and 2 in Table 2). Hence, each of these cases corresponds to the codes applied to two consecutive turns, labelled as concept-representation connection absent (i.e., there was no concept-representation connection in the following turn). Further, each case was annotated by speaker (student or instructor) and representation mode (physical or virtual). Table 3 provides an overview of the dataset.

Table 3: Number of Utterances with Concept-Representation Connection

\begin{tabular}{|c|c|c|c|c|c|c|c|c|}
\hline \multirow{3}{*}{$\begin{array}{l}\text { Mode } \\
\text { Physical }\end{array}$} & \multicolumn{4}{|c|}{ Label } & \multicolumn{4}{|c|}{ Speaker } \\
\hline & \multicolumn{2}{|c|}{ Connection present } & \multicolumn{2}{|c|}{ Connection absent } & \multicolumn{2}{|c|}{ Student } & \multicolumn{2}{|c|}{ Instructor } \\
\hline & 229 & $(7.33 \%)$ & 2,895 & $(92.67 \%)$ & 2,115 & $(67.70 \%)$ & 1,009 & $(32.30 \%)$ \\
\hline Virtual & 67 & $(3.28 \%)$ & 1,976 & $(96.72 \%)$ & 1,780 & $(86.13 \%)$ & 263 & $(12.87 \%)$ \\
\hline
\end{tabular}

The third step was to search for social events that frequently preceded concept-representation connections. Given the focus on social mechanisms, I was interested in discovering which codes cooccur. I used a frequent pattern mining algorithm to identify which codes often occur together (Luna, 2016; Romero, Luna, Romero, \& Ventura, 2011). I ran this algorithm on all codes assigned to the two turns prior to cases separately for with and without concept-representations for physical and virtual representations. This analysis discovered:

1. Frequent discourse patterns for cases with concept-representation connections for physical representations

2. Frequent discourse patterns for cases without concept-representation connections for physical representations

3. Frequent discourse patterns for cases with concept-representation connections for virtual representations

4. Frequent discourse patterns for cases without concept-representation connections for virtual representations

Comparing findings 1 and 2 identifies social events that often precede concept-representation connections with physical representations. Comparing findings 3 and 4 identifies social events that often precede concept-representation connections with virtual representations. Comparing findings 1 and 3 identifies social events common or unique to the representation mode.

Qualitative Analyses were used to examine social mechanisms that characterize the events that often precede concept-representation connections. To this end, I identified cases in the transcript that 
(2017). How do students learn to see concepts in visualizations? Social learning mechanisms with physical and virtual representations. Journal of Learning Analytics, 4(2), 240-263. http://dx.doi.org/10.18608/jla.2017.42.16

correspond to frequent patterns. I then examined discourse prior to the concept-representation connection, starting with the first mention of the concept and/or representation. Thus, the qualitative analysis expanded the unit of analysis and by moving beyond particular social events to understand broader social mechanisms of concept-representation connections.

\section{$3 \quad$ RESULTS}

I first discuss findings for physical representations and virtual representations, followed by comparison of physical and virtual representation modes. In doing so, I present results from frequent pattern analysis together with representative examples from qualitative analysis.

\subsection{Physical Representations}

To identify social events that often precede concept-representation connections with physical representations, I considered patterns found only for cases with a connection-representation connection - but not for cases without a concept-representation connection. Table 4 shows the identified patterns with metrics of support (i.e., how often the codes in the pattern co-occur across all cases in the dataset) and confidence (i.e., how often the presence of one of the codes in the pattern predicts the presence of the other code(s) in the pattern).

Table 4: Frequent Patterns for Physical Representations

\begin{tabular}{lcc}
\hline Frequent pattern & Support & Confidence \\
\hline 1. instructor-assent; student-concept & 0.100 & 0.410 \\
\hline 2. instructor-assent; student-representation & 0.087 & 0.377 \\
\hline 3. instructor-representation-request; instructor-concept-request & 0.074 & 0.684 \\
\hline 4. student-representation; student-concept & 0.201 & 0.803 \\
\hline 5. instructor-assent; student-representation; student-concept & 0.083 & 0.536 \\
\hline
\end{tabular}

NOTE: Underlined = instructor utterances; italics = patterns that overlap with virtual representations.

Several results are worth noting. First, four of five patterns involve instructor utterances, and most of these (three of five patterns) include assent by the instructor. Assent is defined as agreement with a previous statement (see Table 1), often in the form of encouragement (e.g., "mhm," "yeah"). In the identified patterns, such encouragement co-occurs with references to a concept or representation (or both) provided by one of the students or by the instructor. The qualitative analysis provides insights into how assent might encourage concept-representation connections. For example, Jerome and Ira asked the instructor for help in making sense of how to use the electronegativity difference between atoms to determine the polarity of a bond, and how the EPM (Figure 1d) shows this concept. After probing their understanding of electronegativity, the instructor explains electronegativity trends in the periodic table. Ira says: "I knew it had something to do with the electrons," indicating that he understands the relationship between electronegativity and the number of electrons. The instructor assents: "Mmhmm." 
(2017). How do students learn to see concepts in visualizations? Social learning mechanisms with physical and virtual representations. Journal of Learning Analytics, 4(2), 240-263. http://dx.doi.org/10.18608/jla.2017.42.16

Ira continues explaining the concept of electronegativity: "And like how, how one [atom] has more [electrons] and one [atom] has less [electrons]." The instructor assents: "Yeah." Then, Ira connects the representation to electronegativity:

Okay. Since this one has [points at one atom in the representation], okay. Since this one [points at the other atom] has, is more negative than this one [points at first atom], that makes 'em ... so this one's positive [points at second atom], this one's negative [points at first atom]. So it like bonds 'em together. It woulda made sense if I used this one as the fluorine and this one as the nitrogen.

The qualitative analysis suggests that instructors often used assent to indicate that students were on the right path with their reasoning, as illustrated in this excerpt. This, in turn, seems to encourage students to construct concept-representation connections.

A further observation from the frequent pattern analysis is that all patterns involve either a reference to a concept or to a representation. A related finding is that three of five patterns include references to both concepts and representations - either as a request to relate to concepts and representations by the instructor (pattern \#3) or by the students themselves (patterns \#4 and \#5). The qualitative analysis clarifies these patterns. For example, Jazmin and Lennie discuss whether the Lewis structure representation (Figure 1a) shows electronegativity. Jazmin first tries to make sense of electronegativity with a metaphor: "Electronegativity. Oh, you mean, like polarity as in, like, which one is stronger?" Lennie assents: "Yeah, I think so." Jazmin makes sense of electronegativity by elaborating on the metaphor: "Yeah, electronegativity is basically like who's pulling more." Lennie offers a connection to the Lewis structure representation: "Okay. So, it [the Lewis structure] would be kinda showing that, I think. Because, like, because of the electrons that have like being like started in the middle, being like shared." In this example, Jazmin and Lennie first discuss the concept and then connect it to the representation.

In another example, Dirk has constructed a connection between electronegativity and the ball-and-stick representation (Figure 1c), but he is not sure it is correct. He asks the instructor: "I'm so confused. Uh. This is higher [points at one of the atom's electronegativity value in the periodic table], so it just takes it off. It's... And then that. I know that this one just tries to fill as much holes [in the ball-and-stick model] as it can and it will take off like in the shell that it has around it. So..." The instructor assents: "Mmhm. Mmhm. Okay." Dirk continues to elaborate on electronegativity: "Like the atomic number is seven and it has nine and that would take like one more to make it an even ten to fill a spot and that would become six. I mean..." The instructor explains the concept by elaborating on how electronegativity relates to the Octet rule: "I agree with you in that this will give electrons to here and this will give electrons to here to even it out, to make it more stable, and each of its shells are orbital. Um. Let's see. Um. So fluorine is, so fluorine is getting like more electrons, right?" Dirk assents: "Yeah. Yeah." The instructor continues: "Compared to how many each nitrogen atom is getting, right?" Dirk assents: "Yeah." The instructor connects the concept to the representation and asks Dirk to elaborate on this connection: "So, this is 
(2017). How do students learn to see concepts in visualizations? Social learning mechanisms with physical and virtual representations. Journal of Learning Analytics, 4(2), 240-263. http://dx.doi.org/10.18608/jla.2017.42.16

[points at ball-and-stick model], has stronger electronegativity and this has less. So, where do you think electrons are going to want to go more?" Dirk connects the concept to the representation: "Probably here [points at ball-and-stick model]." The instructor paraphrases his response and assents: "To the fluorine. Right." Dirk offers an elaboration of this concept-representation connection but struggles to find the right words: "Is there, aren't these [points at ball-and-stick model] just staying here because they're kind of getting pulled? Like the, the atomic, er... not the atomic, whatever it is..." The instructor offers the right term: "The electrons?" Dirk continues his concept-representation connection: "Yeah, the electrons are getting pulled into there [points at atom in ball-and-stick model] and that's what's, er, that's what's making these stay around. In this like connection [points at bond in ball-and-stick model]." These two examples illustrate the finding from the qualitative analysis that students tend to construct concept-representation connections incrementally.

Taken together, the findings on physical representations suggest that students relied on encouragement from the instructor more so than on encouragement from their fellow students. Receiving encouragement from the instructor - especially when discourse is already focused on a concept or representation - seemed to lead students to elaborate by constructing a concept-representation connection. Further, students were most likely to construct a concept-representation connection when discourse already focused on either a concept or a representation.

\subsection{Virtual Representations}

To identify social events that often preceded concept-representation connections with virtual representations, I again considered patterns found only for cases with a concept-representation connection. Table 5 shows the identified patterns with support and confidence metrics.

The following findings stand out. First, seven of sixteen patterns involve instructor utterances. This ratio seems surprisingly high given that students received considerable support from the educational technology in which the virtual representations were embedded. The instructor circulated the classroom and was available for help upon request. Consequently, when students worked with virtual representations, they generated $86.13 \%$ of the utterances, and instructors only $12.87 \%$ (see Table 3 ). The qualitative analysis provided insights into how instructors helped students make conceptrepresentation connections. For example, Jerome and Ira raise their hand to get help from the instructor. They are stuck on a problem in which they have to explain whether the Lewis structure (see Figure 1e) shows polarity. The instructor comes to the table and asks: "So, you're stuck on polarity?" Jerome confirms: "Yeah." The instructor explains the concept by relating to a metaphor: "Um, have you, okay, so, have you noticed for a battery, what way you put it into the system matters, how there's a plus end and an minus end?" Jerome seems to be able to picture this scenario: "Yeah, yeah. It has the negative charges." The instructor prompts the students to elaborate on this metaphor: "Exactly. So polarity is describing the positive or negative end of something. And so..." Jerome makes a tentative concept-representation connection: "Just with this figure, wouldn't I need to, well I know the valence electrons, wouldn't I need to know the entire thing of electrons?" The instructor prompts further: "Well, 
(2017). How do students learn to see concepts in visualizations? Social learning mechanisms with physical and virtual representations. Journal of Learning Analytics, 4(2), 240-263. http://dx.doi.org/10.18608/jla.2017.42.16

just the valence electrons because..." Jerome tries to expand: "Because, um, it's like a battery because the um..." The instructor encourages him: "It's okay, take your time." Jerome continues to explain the concept-representation connection: "I keep on forgetting the names of 'em. Chlorine has more [points at representation], more of a negative charge and magnesium [points at representation] has more of a positive charge." The qualitative analysis suggests that students often relied on the instructor to explain concepts when they were trying to connect the concept to the representation.

Table 5: Frequent Patterns for Virtual Representations

\begin{tabular}{|c|c|c|c|}
\hline \multicolumn{2}{|c|}{ Frequent pattern } & \multirow{2}{*}{$\begin{array}{c}\text { Support } \\
0.075\end{array}$} & \multirow{2}{*}{$\frac{\text { Confidence }}{0.420}$} \\
\hline 1. & instructor-assent; instructor-concept & & \\
\hline 2. & student-metaConfusion; student-representation & 0.104 & 0.393 \\
\hline 3. & student-metaUnderstanding; student-representation & 0.075 & 0.471 \\
\hline 4. & student-metaUnderstanding; student-concept & 0.075 & 0.476 \\
\hline 5. & student-metaConfusion; student-concept & 0.075 & 0.386 \\
\hline 6. & student-concept; student-assent & 0.134 & 0.388 \\
\hline 7. & student-representation; student-assent & 0.134 & 0.378 \\
\hline 8. & instructor-concept-request; instructor-concept & 0.060 & 0.468 \\
\hline 9. & instructor-representation-request; instructor-representation & 0.060 & 0.468 \\
\hline 10. & $\underline{\text { instructor-representation-request; instructor-concept }}$ & 0.060 & 0.508 \\
\hline 11. & student-assent; instructor-representation; instructor-concept & 0.060 & 0.568 \\
\hline 12. & $\begin{array}{l}\text { student-metaConfusion; student-representation; student- } \\
\text { concept }\end{array}$ & 0.075 & 0.468 \\
\hline 13. & $\begin{array}{l}\text { instructor-representation-request; instructor-representation; } \\
\text { instructor-concept }\end{array}$ & 0.060 & 0.637 \\
\hline 14. & $\begin{array}{l}\text { student-metaUnderstanding; student-concept; student- } \\
\text { representation }\end{array}$ & 0.060 & 0.463 \\
\hline 15. & student-assent; student-concept; student-representation & 0.119 & 0.550 \\
\hline 16. & instructor-representation; student-assent & 0.060 & 0.299 \\
\hline 17. & instructor-assent; student-concept & 0.090 & 0.374 \\
\hline 18. & instructor-assent; student-representation & 0.104 & 0.428 \\
\hline 19. & instructor-representation-request; instructor-concept-request & 0.075 & 0.714 \\
\hline 20. & student-concept; student-representation & 0.254 & 0.792 \\
\hline 21. & instructor-assent; student-representation; student-concept & 0.090 & 0.539 \\
\hline
\end{tabular}

NOTE: Underlined = instructor utterances; italics = overlap with physical representations.

Second, six of sixteen patterns include assent by the instructor (four of six patterns) or a student (two of six patterns). The qualitative analysis sheds light into the role assent may play in encouraging concept- 
(2017). How do students learn to see concepts in visualizations? Social learning mechanisms with physical and virtual representations. Journal of Learning Analytics, 4(2), 240-263. http://dx.doi.org/10.18608/jla.2017.42.16

representation connections. For example, Jerome and Ira are trying to understand which molecule a ball-and-stick model shows (Figure 1g). Ira reads: "Hydrogen. And two oxygen. Or one oxy-, two hy-. Ugh. Is this, I keep forgetting. Is this [points at ball-and-stick model] the oxygen or a hydrogen?" Jerome identifies the chemical formula: "Wait a minute. Okay, so it's $\mathrm{H}^{2} \mathrm{O}$, right?" Ira assents: "Yeah." Jerome offers a concept-representation connection: "Two O [points at ball-and-stick model]." Ira first assents but then corrects Jerome: "Oh yeah. No it's two hydrogen [points at ball-and-stick model]." Jerome revises his concept-representation connection: "These [points at the same atoms in the ball-and-stick model] are oxygen. That's... no, $\mathrm{H}^{2}$... these are hydrogen and that's oxygen. Okay. Good." Overall, the qualitative analysis suggests that assent - be it from a student or an instructor - encouraged students to elaborate their reasoning about a concept or a representation, which was often followed by a concept-representation connection.

Third, four of the seven patterns that involved an instructor utterance also involved an explicit request for the student to relate to a concept or to a representation. This request was always combined with an instructor-generated reference to a concept or to a representation. For example, Elmer and Fay are working on a problem with the EPM representation (Figure 1h). Fay accidentally puts in an answer, which turns out to be correct: "Oops. Didn't mean to do that. Oh wow, I'm good." The instructor, who happens to walk by the students at this moment, prompts the students to explain why their answer is correct: "Do you guys know why that's right?" Elmer is not sure: "Uh." The instructor explains what the size of the two sides of the EPM mean and then asks them to relate the colour in which chlorine is shown to a concept: "So, this one [points at EPM] is kind of showing how big it is. So, whatever atom is right here, this is chlorine. Why is chlorine the redder one?" Elmer connects the red colour in the representation to the electronegativity concept: "Because it has a higher electronegativity." The qualitative analysis suggests that instructors often requested students to connect to concepts and/or representations when students did not provide an explicit explanation for why an answer was correct.

Fourth, six of sixteen patterns included a meta-cognitive utterance by the student, three of them voicing understanding, three of them voicing confusion. All of these meta-cognitive utterances co-occurred with a reference to a concept and/or a representation. None of these meta-cognitive utterances co-occurred with instructor utterances. The qualitative analysis provides insights into why meta-cognitive utterances might have encouraged students to construct concept-representation connections. For example, Lennie and Jazmin are working on a problem with the ball-and-stick model (Figure 1g). Jazmin reads the problem statement, suggests an answer, and requests assent from Lennie: "Water has a negative charge, local negative charge by... hydrogen. By the hydrogen atom?" Lennie voices his confusion: "Maybe. I don't really know. I don't understand it." Jazmin explains the concept to Lennie while using the representation to illustrate the concept: "Oh, I get it. So you know how, you know there's hydrogen [points at ball-and-stick model], there's oxygen [points at ball-and-stick model] $\mathrm{H}^{2} \mathrm{O}$. What's... so um, which one is pulling more? And they're saying, which one is, which one is pulling more. So it is the oxygen." Later, Jazmin and Lennie are working on a similar problem that uses the Lewis structure representation (Figure 1e). When asked whether the Lewis structure shows polarity, Lennie offers: “I'd 
(2017). How do students learn to see concepts in visualizations? Social learning mechanisms with physical and virtual representations. Journal of Learning Analytics, 4(2), 240-263. http://dx.doi.org/10.18608/jla.2017.42.16

be able to tell that they're pulling the same." Jazmin asks Lennie to make a meta-cognitive statement: "Are you sure?" Lennie reaffirms his understanding with a meta-cognitive statement: "I think, I think so. That they're like pulling the same." Jazmin voices her disagreement by constructing a conceptrepresentation connection, pointing out that the Lewis structure does not show polarity: "Not necessarily. Because, I don't think you would be able to, because, without already knowing what the, what the pulls were, you wouldn't be able to know." These two examples illustrate that when one student reflected on his/her own understanding, this seemed to prompt the other student to correct the student's reasoning.

Finally, all frequent patterns included a reference to a concept or representation. A related result is that seven of sixteen patterns included a reference to both concept and representation (either as the instructor's request for the student to relate to either, or as a direct reference by instructor or student). For example, Hanna and Greta discuss why the Lewis structure representation (Figure 1e) was flagged as incorrect. Hanna reflects on the representation: "Maybe, you just drew the lines too long." Greta disagrees: "It doesn't matter the size of the bond." She connects the representation to the length of the bond, correctly stating that the Lewis structure does not depict bond length. A little later, they are adding electrons to the Lewis structure, which are shown as dots. The electrons are flagged as incorrect, in red. Hanna tries to make sense of the mistake: "They're red. They specifically do not want us to... [reads error message] Oh, so what we have is right. We just need to add something else to it." Greta interprets the error message by relating the dots to the concept of electrons: "Yeah. How many do we need? It's something about the electrons, so..." Hanna realizes the dots show the electrons, thereby making a concept-representation connection: "Alright. Wait. These are, represent electrons?" Greta confirms Hanna's concept-representation connection: "Mmhm." The qualitative analysis revealed that students often referred to the concept and/or representation in previous turns before constructing a concept-representation connection.

In sum, the findings from the frequent pattern analysis and from the qualitative analysis revealed several social mechanisms that often preceded concept-representation connections for virtual representations. First, instructors were often involved in discourse that preceded conceptrepresentation connections. This finding suggests that students need help from an instructor to construct concept-representation connections, even when supported by an educational technology. Second, assent by students and instructors played a large role in discourse prior to conceptrepresentation connections. This finding suggests that encouragement can help students construct a concept-representation connection - regardless of whether it is provided by a student or an instructor. Third, the frequent pattern analysis showed that instructors often explicitly prompted students to elaborate on a previously mentioned concept or representation. The qualitative analysis suggests that such prompts served to offset shallow engagement in sense-making by students. Fourth, when students did not receive support from an instructor, meta-cognitive statements about their own understanding of a concept or a representation often preceded concept-representation connections. For example, after a student voiced confusion about a concept, his/her partner may use a representation to explain a 
(2017). How do students learn to see concepts in visualizations? Social learning mechanisms with physical and virtual representations. Journal of Learning Analytics, 4(2), 240-263. http://dx.doi.org/10.18608/jla.2017.42.16

concept to him/her. Finally, students were most likely to construct a concept-representation connection when the discourse was already focused on a concept or on a representation. Hence, the social mechanisms through which students construct concept-representation connections seem to be incremental and distributed across collaborating students.

\subsection{Comparing Physical and Virtual Modes}

Finally, I investigated whether social events that often precede concept-representation connections differ by representation modes as they are embedded in their particular social contexts. The following commonalities are worth highlighting. First, all patterns found for physical representations were also found for virtual representations. In particular, instructors play a prominent role both for physical and virtual representations. These findings suggest that the role of an instructor is critical to student success in constructing concept-representation connections, regardless of representation mode and regardless of the availability of the instructor or the availability of technology-based support. With respect to virtual representations, this result is surprising because the instructor played a less prominent role for virtual representations. Recall that virtual representations were embedded in an educational technology that provided support for connection making and that the instructor was available upon request to students. By contrast, for physical representations, each student pair was assigned an instructor who readily provided support upon request. The discourse data reflects this setup: When students worked with virtual representations, $12.87 \%$ of all utterances were generated by instructors (see Table 3 ). By contrast, when they worked with physical representations, $32.30 \%$ of all utterances were generated by an instructor (see Table 3). Yet, when students worked with virtual representations, seven of sixteen patterns involved an instructor utterance (of $12.87 \%$ instructor utterances). When students worked with physical representations, four of five patterns involved an instructor utterance (of $32.30 \%$ instructor utterances). The qualitative analysis revealed that for physical representations, instructors encouraged and prompted students to construct concept-representation connections. When students worked with virtual representations, explicit prompts seemed to be more prevalent and seemed to focus students on the concept and representation when they offered a shallow explanation.

A second common characteristic across representation modes was assent to reasoning that was already focused on a concept or representation. The qualitative analysis provides further evidence for this observation. Assent from instructors seemed to signal to students that their reasoning about the concept or the representation was on the right track, which seemed to encourage them to elaborate on their concept-representation connections. This social mechanism resulted in an incremental way of constructing concept-representation connections across students and instructors, regardless of representation mode.

Several differences between representation modes are worth highlighting. First, students made fewer concept-representation connections with virtual representations (3.28\%; see Table 3 ) than with physical representations (7.33\%). In light of the finding that instructors play a critical role for students' conceptrepresentation connections, it may be that the lower involvement of an instructor when students 
(2017). How do students learn to see concepts in visualizations? Social learning mechanisms with physical and virtual representations. Journal of Learning Analytics, 4(2), 240-263. http://dx.doi.org/10.18608/jla.2017.42.16

worked with virtual representations may account for this difference. Indeed, the qualitative analysis suggests that students tended to engage in shallow discussions of concepts and representations. Unless prompted by an instructor to elaborate on their reasoning, they may have failed to construct conceptrepresentation connections.

Second, two types of social events frequently preceded concept-representation connections when students worked with virtual representations that did not involve instructors. First, for physical representations, only instructor assent frequently preceded concept-representation connections. By contrast, for virtual representations, instructor or student assent frequently preceded conceptrepresentation connections. The qualitative analysis suggests that student assent served a similar role as instructor assent, namely to encourage the other student to elaborate. Second, meta-cognitive utterances that voiced confusion or understanding of concepts or representations seemed to serve a prominent role in encouraging concept-representation connections only for virtual representations. Given that none of the patterns that included meta-cognitive utterances included instructor utterances, it seems that meta-cognitive utterances are a major mechanism by which students can encourage one another to construct concept-representation connections in the absence of instructor support. The qualitative analysis suggests that meta-cognitive utterances prompted the other student to explain concepts or representations that may have been misunderstood. The student's explanation often involved a concept-representation connection. These findings suggest that assent and meta-cognitive statements are social mechanisms through which students can take responsibility for collaboratively constructing concept-representation connections without the support of an instructor. By contrast, for physical representations, students seemed to rely more on instructor support to evaluate their understanding, which may explain why meta-cognitive utterances were less prevalent.

Finally, more frequent patterns were found for virtual representations (sixteen frequent patterns) than for physical representations (five frequent patterns). This finding suggests physical representations afforded fewer types of social events that seemed to encourage concept-representation connections. I see two possible explanations for this finding. First, it might be that the educational technology provided support that offered additional pathways to concept-representation connections even when instructor support was not available. Indeed, because virtual representations were embedded in an educational technology, student interactions were more structured than with physical representations. This structure may have enabled students to support one another, for instance, via student-generated metacognitive utterances. By contrast, interactions with physical representations were less structured, so that students may have failed to construct concept-representation connections without instructor support. Second, it might be that instructor guidance in general yields more uniform social interactions. It may be that when instructors are more readily available, students may rely on their support even if they do not need it. Hence, the presence of an instructor may have diminished student willingness to explore additional self-directed pathways to concept-representation connections. A future study should test whether students can construct connections via additional pathways when working on physical representations without instructor support. 
(2017). How do students learn to see concepts in visualizations? Social learning mechanisms with physical and virtual representations. Journal of Learning Analytics, 4(2), 240-263. http://dx.doi.org/10.18608/jla.2017.42.16

\section{DISCUSSION}

My goal was to investigate the representation dilemma: how do novice students learn to see concepts in visual representations? I investigated social mechanisms through which students construct conceptrepresentation connections. In particular, I considered how physical and virtual representations and the social context in which they are commonly embedded affects which social events often precede students' concept-representation connections. Using frequent pattern mining, I identified such social events for physical and virtual representations. Qualitative analysis was used to interpret the social mechanisms that may underlie these frequent patterns.

One major finding is that the nature of the social support available to students in the social context of physical and virtual representations accounts for most concept-representation connections. Regardless of representation mode, instructors play a crucial role in encouraging students to elaborate on connections between previously mentioned concepts and representations. It is not surprising that instructors play a critical role for student learning with physical representations because students have no other way of receiving feedback and assistance. However, the importance of instructors for virtual representations is surprising because the virtual representations were embedded in an educational technology specifically designed to support students in constructing concept-representation connections (and shown to be successful in doing so; Rau, 2015). This study suggests that instructor support is critically important even in a learning context in which students are often thought to be more independent because they receive considerable support from an educational technology. This suggests that technology-based support cannot "replace" instructor support - at least not when students have little prior knowledge about the concepts and representations.

A further major finding is that, regardless of representation mode, a previous relation to a concept or a representation plays an important role in encouraging concept-representation connections. This finding suggests that the conceptual process by which students make concept-representation connections is mediated by a gradual and incremental social mechanism. Specifically, students may first discuss a concept or a representation separately from one another before they negotiate the connection between the two.

Finally, the results suggest that meta-cognitive statements can encourage students to construct concept-representation connections when they work on virtual representations. Meta-cognitive statements were the only social event that frequently preceded concept-representation connections in the absence of an instructor. The social mechanism underlying this effect may be that a meta-cognitive statement by one student prompts the other to explain the given concept by connecting it to the representation. 
(2017). How do students learn to see concepts in visualizations? Social learning mechanisms with physical and virtual representations. Journal of Learning Analytics, 4(2), 240-263. http://dx.doi.org/10.18608/jla.2017.42.16

\subsection{Limitations and Future Directions}

Several limitations of the present analysis should be considered when interpreting these results. First, as previously mentioned, this paper sought to address the representation dilemma. That is, I focused on how novice students come to see novel concepts in novel representations. Because students in this study were novice students with very limited prior knowledge about the concepts and representations, we do not know if the results generalize to more advanced students. One might speculate that the importance of the instructor decreases as student understanding of the content increases, especially when students have access to technology-based support for virtual representations. The results suggest that students incrementally construct concept-representation connections by first focusing on a concept or a representation alone before connecting them. One might speculate that the incremental nature of this process plays a lesser role when students have preliminary experience with the representations or the concepts. Hence, future research should investigate which social events are associated with concept-representation connections for more advanced students. A related limitation is that many utterances did not involve concept-representation connections. Consequently, the overall support and confidence for the discovered patterns is relatively low. Concept-representation connections are one of many mechanisms of student learning, so future research may apply the present analysis to other social (or conceptual) mechanisms of learning.

Second, the study was observational in nature. Its goal was to uncover social mechanisms of conceptual learning with different representation modes and their respective social contexts. Given the focus on social mechanisms, this study did not consider non-verbal events. Given the observational nature of this study, it does not attempt to make causal claims about which instructional interventions are effective. Nonetheless, results offer new hypotheses about instructional support for concept-representation connections. Such support may be most effective if it takes advantage of the social events identified in this study. In particular, one might hypothesize that instruction should be designed to maximize instructor capacity to assist students, regardless of representation mode. One might also hypothesize that interventions with virtual representations are particularly effective if students are prompted (or trained) in monitoring their own understanding and communicate their meta-cognitive assessments to their partner. These hypotheses also apply to blending interventions that combine physical and virtual representations. Experiments that allow for causal claims can test these hypotheses.

Third, one of the major findings was that the availability of instructor support affects how students construct concept-representation connections. While this study investigated representation modes in the social context in which they are typically embedded, there are other social contexts that were not investigated in this study. Hence, future research should examine physical and virtual representations in a larger variety of social contexts that differ with respect to the availability of instructor support. Relatedly, future research on blended interventions should also consider how various social contexts might affect student ability to understand representations depict concepts. 
(2017). How do students learn to see concepts in visualizations? Social learning mechanisms with physical and virtual representations. Journal of Learning Analytics, 4(2), 240-263. http://dx.doi.org/10.18608/jla.2017.42.16

Finally, an assumption underlying this analysis is that concept-representation connections are a "desirable" educational outcome. While much research documents the importance of conceptrepresentation connections for student learning (Ainsworth, 2006; Gilbert, 2005; Kozma \& Russell, 2005b; NRC, 2006; Uttal \& O'Doherty, 2008), it is worth mentioning that the present study did not assess learning gains. Future research should include pre-tests and post-tests of domain-knowledge and test whether concept-representation connections mediate the effectiveness of physical and virtual representations and of blending interventions that combine both representation modes.

\section{CONCLUSION}

The present study contributes to research on the representation dilemma by providing new insights into how novice students construct connections between novel concepts to novel representations. At a theoretical level, this study suggests that the availability of instructor support in the context in which physical and virtual representations are typically implemented affects how students construct conceptrepresentation connections. The finding highlights the importance of instructor support, even when students work with virtual representations within an educational technology that already provides much support - a social context assumed to make students more independent of instructor support. Yet, in the absence of an instructor, students can support one another, in particular via meta-cognitive statements and encouragement to elaborate. At a practical level, this study suggests that physical and virtual representations may be most effective for novice students if they are implemented in social contexts with instructor support. Further, interventions with virtual representations may benefit from meta-cognitive support.

In sum, this study shows that concept-representation connections emerge in a socially mediated coconstructive process that is incremental and that is affected by the social support system available in the given context. This finding highlights the importance of considering social affordances and thereby extends prior research on representation modes that has focused on cognitive affordances.

\section{REFERENCES}

Ainsworth, S. (2006). DeFT: A conceptual framework for considering learning with multiple representations. Learning and Instruction, 16(3), 183-198. http://dx.doi.org/10.1016/j.learninstruc.2006.03.001

Ainsworth, S. (2008). The educational value of multiple-representations when learning complex scientific concepts. In J. K. Gilbert, M. Reiner, \& A. Nakama (Eds.), Visualization: Theory and practice in science education (pp. 191-208). Netherlands: Springer. http://dx.doi.org/10.1007/978-1-40205267-5_9

Ainsworth, S., Bibby, P., \& Wood, D. (2002). Examining the effects of different multiple representational systems in learning primary mathematics. Journal of the Learning Sciences, 11(1), 25-61. http://dx.doi.org/10.1207/S15327809JLS1101_2

Airey, J., \& Linder, C. (2009). A disciplinary discourse perspective on university science learning: 
(2017). How do students learn to see concepts in visualizations? Social learning mechanisms with physical and virtual representations. Journal of Learning Analytics, 4(2), 240-263. http://dx.doi.org/10.18608/jla.2017.42.16

Achieving fluency in a critical constellation of modes. Journal of Research in Science Teaching, 46(1), 27-49. http://dx.doi.org/10.1002/tea.20265

Bakker, S., Antle, A. N., \& Van Den Hoven, E. (2012). Embodied metaphors in tangible interaction design. Personal and Ubiquitous Computing, 16(4), 433-449. http://dx.doi.org/10.1007/s00779-0110410-4

Bodemer, D., \& Faust, U. (2006). External and mental referencing of multiple representations. Computers in Human Behavior, 22(1), 27-42. http://dx.doi.org/10.1016/j.chb.2005.01.005

Bodner, G. M., \& Domin, D. S. (2000). Mental models: The role of representations in problem solving in chemistry. University Chemistry Education, 4(1), 24-30.

Boulter, C. J., \& Gilbert, J. K. (2000). Challenges and opportunities of developing models in science education. In J. K. Gilbert \& C. J. Boulter (Eds.), Developing models in science education (pp. 343362). Netherlands: Kluwer Adademic Publishers. http://dx.doi.org/10.1007/978-94-010-08761 1_18

Chi, M. T., Bassok, M., Lewis, M. W., Reimann, P., \& Glaser, R. (1989). Self-explanations: How students study and use examples in learning to solve problems. Cognitive Science, 13(2), 145-182. http://dx.doi.org/10.1016/0364-0213(89)90002-5

Chini, J. J., Madsen, A., Gire, E., Rebello, N. S., \& Puntambekar, S. (2012). Exploration of factors that affect the comparative effectiveness of physical and virtual manipulatives in an undergraduate laboratory. Physical Review Special Topics: Physics Education Research, 8(1). http://dx.doi.org/10.1103/PhysRevSTPER.8.010113

Clements, D. H. (1999). 'Concrete' manipulatives, concrete ideas. Contemporary Issues in Early Childhood, 1(1), 45-60. http://dx.doi.org/10.2304/ciec.2000.1.1.7

de Jong, T., Linn, M. C., \& Zacharia, Z. C. (2013). Physical and virtual laboratories in science and engineering education. Science, 340(6130), 305-308. http://dx.doi.org/10.1126/science.1230579

Dori, Y. J., \& Barak, M. (2001). Virtual and physical molecular modeling: Fostering model perception and spatial understanding. Educational Technology \& Society, 4(1), 61-74.

Dreher, A., \& Kuntze, S. (2014). Teachers facing the dilemma of multiple representations being aid and obstacle for learning: Evaluations of tasks and theme-specific noticing. Journal für MathematikDidaktik, 1-22. http://dx.doi.org/10.1007/s13138-014-0068-3

Finkelstein, N. D., Adams, W. K., Keller, C. J., Kohl, P. B., Perkins, K. K., Podolefsky, N. S., . . LeMaster, R. (2005). When learning about the real world is better done virtually: A study of substituting computer simulations for laboratory equipment. Physical Review Special Topics: Physics Education Research, 1, 1-8. https://doi.org/10.1103/PhysRevSTPER.1.010103

Gentner, D. (1983). Structure-mapping: A theoretical framework for analogy. Cognitive Science, 7(2), 155-170. http://dx.doi.org/10.1207/s15516709cog0702_3

Gilbert, J. K. (2005). Visualization: A metacognitive skill in science and science education. In J. K. Gilbert (Ed.), Visualization: Theory and practice in science education (pp. 9-27). Dordrecht, Netherlands: Springer. http://dx.doi.org/10.1007/1-4020-3613-2_2

Jaakkola, T., Nurmi, S., \& Veermans, K. (2011). A comparison of students' conceptual understanding of 
(2017). How do students learn to see concepts in visualizations? Social learning mechanisms with physical and virtual representations. Journal of Learning Analytics, 4(2), 240-263. http://dx.doi.org/10.18608/jla.2017.42.16

electric circuits in simulation only and simulation-laboratory contexts. Journal of Research in Science Teaching, 48(1), 71-93. http://dx.doi.org/10.1002/tea.20386

Justi, R., \& Gilbert, J. K. (2002). Models and modelling in chemical education. In O. de Jong, R. Justi, D. F. Treagust, \& J. H. van Driel (Eds.), Chemical education: Towards research-based practice (pp. 4768). Dordrecht, Netherlands: Kluwer Academic Publishers.

Klahr, D., Triona, L. M., \& Williams, C. (2007). Hands on what? The relative effectiveness of physical versus virtual materials in an engineering design project by middle school children. Journal of Research in Science Teaching, 44(1), 183-203. http://dx.doi.org/10.1002/tea.20152

Kozma, R., \& Russell, J. (2005a). Multimedia learning of chemistry. In R. E. Mayer (Ed.), The Cambridge handbook of multimedia learning (pp. 409-428). New York: Cambridge University Press.

Kozma, R., \& Russell, J. (2005b). Students becoming chemists: Developing representational competence. In J. Gilbert (Ed.), Visualization in science education (pp. 121-145). Dordrecht, Netherlands: Springer. http://dx.doi.org/10.1007/1-4020-3613-2

Luna, J. M. (2016). Pattern mining: Current status and emerging topics. Progress in Artificial Intelligence, 1-6. http://dx.doi.org/10.1007/s13748-016-0090-4

Manches, A., O'Malley, C., \& Benford, S. (2010). The role of physical representations in solving number problems: A comparison of young children's use of physical and virtual materials. Computers \& Education, 54(3), 622-640. http://dx.doi.org/10.1016/j.compedu.2009.09.023

McElhaney, K. W., Chang, H. Y., Chiu, J. L., \& Linn, M. C. (2015). Evidence for effective uses of dynamic visualisations in science curriculum materials. Studies in Science Education, 51(1), 49-85. http://dx.doi.org/10.1080/03057267.2014.984506

Michalchik, V., Rosenquist, A., Kozma, R., Kreikemeier, P., \& Schank, P. (2008). Representational resources for constructing shared understandings in the high school chemistry classroom. In J. K. Gilbert, M. Reiner, \& M. B. Nakhleh (Eds.), Visualization: Theory and practice in science education (pp. 233-282). Dordrecht, Netherlands: Springer. http://dx.doi.org/10.1007/978-14020-5267-5_11

Muller, M. (2014). Curiosity, creativity, and surprise as analytic tools: Grounded theory method. In J. S. Olson \& W. A. Kellogg (Eds.), Ways of knowing in $\mathrm{HCl}$ (pp. 25-48). New York: Springer.

NRC. (2006). Learning to think spatially. Washington, DC: National Academies Press.

Olympiou, G., \& Zacharia, Z. C. (2012). Blending physical and virtual manipulatives: An effort to improve students' conceptual understanding through science laboratory experimentation. Science Education, 96(1), 21-47. http://dx.doi.org/10.1002/sce.20463

Rau, M. A. (2015). Enhancing undergraduate chemistry learning by helping students make connections among multiple graphical representations. Chemistry Education Research and Practice, 16, 654669. http://dx.doi.org/10.1039/C5RP00065C

Rau, M. A. (2016). Conditions for the effectiveness of multiple visual representations in enhancing STEM learning. Educational Psychology Review, 1-45. http://dx.doi.org/10.1007/s10648-016-9365-3

Rau, M. A., Aleven, V., \& Rummel, N. (2015). Successful learning with multiple graphical representations and self-explanation prompts. Journal of Educational Psychology, 107(1), 30-46. http://dx.doi.org/10.1037/a0037211 
(2017). How do students learn to see concepts in visualizations? Social learning mechanisms with physical and virtual representations. Journal of Learning Analytics, 4(2), 240-263. http://dx.doi.org/10.18608/jla.2017.42.16

Rau, M. A., Aleven, V., Rummel, N., \& Pardos, Z. (2014). How should intelligent tutoring systems sequence multiple graphical representations of fractions? A multi-methods study. International Journal of Artificial Intelligence in Education, 24(2), 125-161. http://dx.doi.org/10.1007/s40593$\underline{013-0011-7}$

Romero, C., Luna, J. M., Romero, J. R., \& Ventura, S. (2011). RM-Tool: A framework for discovering and evaluating association rules. Advances in Engineering Software, 42(8), 566-576. http://dx.doi.org/10.1016/j.advengsoft.2011.04.005

Roschelle, J. (1992). Learning by collaborating: Convergent conceptual change. Journal of the Learning Sciences, 2(3), 235-276. http://dx.doi.org/10.1207/s15327809jls0203_1

Saldana, J. (2016). An introduction to codes and coding. In J. Seaman (Ed.), The coding manual for qualitative researchers (pp. 1-31). London: SAGE Publications.

Schnotz, W. (2005). An integrated model of text and picture comprehension. In R. E. Mayer (Ed.), The Cambridge handbook of multimedia learning (pp. 49-69). New York: Cambridge University Press.

Schnotz, W. (2014). An integrated model of text and picture comprehension. In R. E. Mayer (Ed.), The Cambridge handbook of multimedia learning (2 ed., pp. 72-103). New York: Cambridge University Press.

Seufert, T., \& Brünken, R. (2006). Cognitive load and the format of instructional aids for coherence formation. Applied Cognitive Psychology, 20, 321-331. http://dx.doi.org/10.1002/acp.1248

Strickland, A. M., Kraft, A., \& Bhattacharyya, G. (2010). What happens when representations fail to represent? Graduate students' mental models of organic chemistry diagrams. Chemistry Education Research and Practice, 11(4), 293-301. http://dx.doi.org/10.1039/CORP90009E

Tortosa, M. (2012). The use of microcomputer based laboratories in chemistry secondary education: Present state of the art and ideas for research-based practice. Chemistry Education Research and Practice, 13(3), 161-171. http://dx.doi.org/10.1039/C2RP00019A

Uttal, D. H., \& O'Doherty, K. (2008). Comprehending and learning from 'visualizations': A developmental perspective. In J. Gilbert (Ed.), Visualization: Theory and practice in science education (pp. 5372). Netherlands: Springer. http://dx.doi.org/10.1007/978-1-4020-5267-5_3

Vygotsky, L. S. (1978). Internalization of higher psychological functions. In M. W. Cole, V. John-Steiner, S. Scribner, \& E. Souberman (Eds.), Mind in society (pp. 52-57). Cambridge, MA: Harvard University Press.

Wertsch, J. V. (1997). Properties of mediated action. In J. V. Wertsch (Ed.), Mind as action (pp. 23-72). New York: Oxford University Press.

Wertsch, J. V., \& Kazak, S. (2011). Saying more than you know in instructional settings. In T. Koschmann (Ed.), Theories of learning and studies of instructional practice (pp. 153-166). New York: Springer. http://dx.doi.org/10.1007/978-1-4419-7582-9_9

Winn, W., Stahr, F., Sarason, C., Fruland, R., Oppenheimer, P., \& Lee, Y. L. (2006). Learning oceanography from a computer simulation compared with direct experience at sea. Journal of Research in Science Teaching, 43(1), 25-42. http://dx.doi.org/10.1002/tea.20097

Wu, H. K., Krajcik, J. S., \& Soloway, E. (2001). Promoting understanding of chemical representations: Students' use of a visualization tool in the classroom. Journal of Research in Science Teaching, 
(2017). How do students learn to see concepts in visualizations? Social learning mechanisms with physical and virtual representations. Journal of Learning Analytics, 4(2), 240-263. http://dx.doi.org/10.18608/jla.2017.42.16

38(7), 821-842. http://dx.doi.org/10.1002/tea.1033

Zacharia, Z. C., Loizou, E., \& Papaevripidou, M. (2012). Is physicality an important aspect of learning through science experimentation among kindergarten students? Early Childhood Research Quarterly, 27(3), 447-457. http://dx.doi.org/10.1016/j.ecresq.2012.02.004

Zhang, Z. H., \& Linn, M. C. (2011). Can generating representations enhance learning with dynamic visualizations? Journal of Research in Science Teaching, 48(10), 1177-1198. http://dx.doi.org/10.1002/tea.20443 